DOI: https://doi.org/10.24867/02EF03Krstic

\title{
ISPITIVANJE PONOVLJIVOSTI ŠTAMPE NA GRAFIČKOM SISTEMU XEROX DOCUCOLOR 250
}

\section{ANALYSIS OF PRINT REPEATABILITY ON PRINTING SYSTEM XEROX DOCUCOLOR 250}

\begin{abstract}
Miloš Krstić, Nemanja Kašiković, Ivana Oblast - GRAFIČKO INŽENJERSTVO I DIZAJN

Kratak sadržaj - U ovom radu prikazano je istraživanje vezano za ponovljivost digitalne tehnike štampe elektrofotografije sa suvim tonerom Za otiskivanje je korišćen grafički sistem Xerox DocuColor 250. Za potrebe ispitivanja ponovljivosti kreirana je test karta, koja je štampana na tri različite podloge, a zatim su izvršena objektivna merenja Lab vrednosti $i$ optičkih gustina polja na test karti, sa ciljem izračunavanja razlika $u$ boji, čijom analizom je kasnije utvrđen kvalitet ponovljivosti štampe. Vršena je analiza vremenske $i$ prostorne ponovljivosti.
\end{abstract}

Ključne reči: Digitalna štampa, elektrofotografija, ponovljivosti štampe

\begin{abstract}
This paper presents the research related to print repeatabiliy of digital printing technique, dry-toner electrophotography. All sheets were printed on the printing system Xerox DocuColor 250. For the needs of repeatability analysis, the test form was created, and later printed, on three different printing substrates. Measuring of Lab coordinates and optical density values was performed in order to calculate color differences. By analyzing those color differences, conclusions are made concerning print repeatability, both temporal and spatial.
\end{abstract}

Keywords: Digital printing, electrophotography, print repeatability

\section{UVOD}

Kada se govori o kvalitetu štampe uglavnom se misli na preciznost (dobijanje otiska koji je najpribližniji nekom referentnom otisku ili referentnim vrednostima). Međutim, ponovljivost štampe je podjednako bitan parametar, koji određuje koliko je štamparski sistem konzistentan, i kolika su odstupanja između otisaka istog tiraža. Zahtevi za ponovljivom štampom postoje od njenog nastanka, iako je potreba za dobijanjem vernih reprodukcija originala postojala i pre njenog otkrića.

Kada je reč o štampi u boji, preciznost boje i njena ponovljivost su od krucijalnog značaja za sve tehnike štampe, i može se reći da ponovljivost u smislu reprodukcije boja predstavlja jedan od glavnih zadataka štampe danas.

\section{NAPOMENA:}

Ovaj rad proistekao je iz master rada čiji mentor je bio dr Nemanja Kašiković, vanr prof.
Što se tiče digitalne štampe, iako postoji veliki broj prednosti u odnosu na konvencionalne tehnike štampe, upravo ponovljivost i održanje kvaliteta tokom celog tiraža predstavlja jedan od najtežih zahteva koje digitala štampa mora da ispuni. Razlog za to je prvenstveno nepostojanje fizičke štamparske forme, kao nosioca slike. Kako se ta slika stvara iznova za svaki otisak, jasno je da je dobijanje identičnih kopija na ovaj način dosta teže i problematičnije [1].

\section{PONOVLJIVOST ŠTAMPE}

Kada se govori o ponovljivosti u štampi, najčešće se pod tim podrazumeva konzistentna štampa celog tiraža, ili više tiraža istog proizvoda, pri čemu su odstupanja u boji u određenim granicama tolerancije. Ovo predstavlja vremensku ponovljivost (temporal repeatability). Pored vremenske ponovljivosti, postoji i prostorna ponovljivost (spatial repeatability), koja se odnosi na ujednačenost elemenata koji se nalaze na različitim pozicijama na tabaku.

Vremenska i prostorna ponovljivost nisu zavisne, i na njih utiču različiti faktori, u zavisnosti od toga o kojoj se tehnici štampe radi. Može se reći da prostorna ponovljivost oslikava mehaničku kalibraciju mašine za štampu, dok vremenska prikazuje varijacije u zavisnosti od vremena, $\mathrm{tj}$. stabilnost procesa štampe [2].

Kao i kod ostalih tehnika štampe, i kod elektrofotografije postoje faktori koji su svojstveni samo ovoj tehnici štampe, a koji imaju uticaj na njen kvalitet, kao i na ponovljivost.

Kod elektrofotografske štampe, za postizanje ponovljivosti neophodno je:

- generisanje ujednačenog naelektrisanja fotoprovodnog cilindra pre oslikavanja,

- generisanje istih elektrostatičkih sila za prihvatanje tonera u fazi razvijanja,

- generisanje istih elektrostatičkih sila za prenos tonera sa fotoprovodnog cilindra na podlogu ili međuprenosač,

- $\quad$ konzistentno čišćenje preostalih čestica tonera sa fotoprovodnog cilindra [3].

Međutim, teško je ispuniti sve navedene uslove jer su čak i najbolje dizajnirani elektrofotografski sistemi podložni nekontrolisanim promenana materijala (tonera, fotoreceptora i podloge za štampu) i faktora okoline 
(ambijentalna temperatura, relativna vlažnost vazduha, nadmorska visina itd.) [3].

$\mathrm{Na}$ ponovljivost štampe kod elektrofotgrafije utiču štamparski sistem, toner i podloga za štampu. Jedan od najvažnijih faktora štamparskog sistema je kvalitet i uniformnost fotoreceptora. Što se tiče tonera, važna je uniformnost veličine i oblika čestica, ujednačenost naboja, hemijska i fizička struktura itd. Varijacije pomenutih parametara svakako mogu dovesti do neuniformnosti otiska. Ipak, ovo varijacije su jako male, pa se pre svega odnose na mikro neuniformnosti i pojavu šara. Neravnomeran prenos tonera je jedan od glavnih razloga za lošu ponovljivost štampe. Pored elektrofotografskog sistema i tonera, za održanje konzistentnog kvaliteta i ponovljivu štampu veoma su bitna i svojstva podloge koja se koristi. Neuniformnost boje na otisku, kao i veće prostorne varijacije, prouzrokovane su neizbežnom činjenicom da se količina boje koja se prenese na podlogu tokom štampanja uvek razlikuje u određenoj meri, odnosno da prenos tonera nije uniforman, na šta ukazuju različita istraživanja vezana za ovaj problem [4].

\section{EKSPERIMENTALNI DEO}

Za potrebe ovog master rada, $u$ svrhu ispitivanja ponovljivosti štampe bilo je potrebno kreirati test kartu (Slika 1). Test karta je projektovana tako da se može analizirati prostorna i vremenska ponovljivost štampe. $\mathrm{Na}$ sredini test karte nalazi se klin koji je preuzet sa test karte Idealliance digital press form, za merenje kratkoročne ponovljivosti. Ovaj klin sadrži primarne i sekundarne boje u punim i srednjim tonovima. Pored toga, za ispitivanje ponovljivosti raspoređeni su klinovi sa poljima punog tona za četiri procesne boje, na 8 pozicija na tabaku (označene brojevima 1-8 na slici 1). Veličina polja na svim klinovima je $8 \times 8 \mathrm{~mm}$, imajući u vidu sposobnosti mernog uređaja.

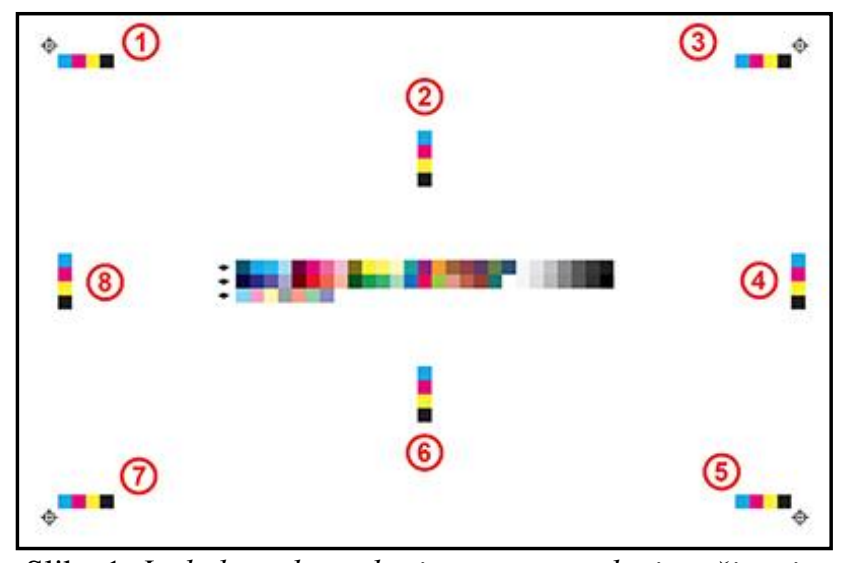

Slika 1. Izgled test karte kreirane za potrebe istraživanja

Test karta je odštampana na tri tipa podloge - kunstdruk, ofsetni papir i tripleks karton, pri čemu je za sva tri slučaja test karta štampana u intervalu od 1 sat i 24 sata od prve štampe, radi ispitivanja vremenske ponovljivosti, u skladu sa Idealliance programom sertifikacije za digitalne štamparske mašine (Idealliance Digital Press Certification Program, verzija 2.3.6). Za format test karte izabran je prošireni A3 format, ujedno i maksimalni format mašine.
Kako bi se okarakterisala podloga za štampu izmerena je njena hrapavost, belina i žutoća, a zatim su vršena spektrofotometrijska merenja, kao i analiza preciznosti registra uz pomoć digitalnog mikroskopa.

\subsection{Korišćeni uređaji i materijali}

Za objektivno merenje spektrofotometrijskih vrednosti korišćen je spektrofotometar Techkon SpectroDens. Ovaj uređaj ima mogućnost izračunavanja spektralnih, kolorimetrijskih i denzitometrijskih veličina. U ovom radu mernim uređajem SpectroDens merene su Lab koordinate $\mathrm{i}$ vrednosti optičkih gustina mernih polja sa test karte, kao i belina i žutoća podloge. Za analizu preciznosti registra korišćen je USB mikroskop Veho VMS-004D, dok je za merenje površinske hrapavosti podloge korišćen stilusni profilometar TR-200.

Što se tiče same štamparske mašine, korišćen je sistem Xerox DocuColor 250. Ovo je srednje produktivna mašina, sa Single-pass sistemom gradnje, i brzinom štampe od 50 tabaka u minutu. Podržava velik broj različitih podloga, sa gramaturama u opsegu od 64 do 300 $\mathrm{g} / \mathrm{m}^{2}$, i koristi hemijski dobijen EA toner (visoko sjajni). Prenos tonera na podlogu vrši se indirektno, putem prenosnog medijuma (transfernog remena). Ova mašina za oslikavanje koristi VCSEL ROS sistem, pa je maksimalna rezolucija 2400x2400 dpi.

Štampa test karte vršena je na tri tipa podloge - ofsetnom papiru, kunstdruk papiru i tripleks kartonu, pri čemu su sve podloge različitog sastava, gramatura i karakteristika. Ofsetni papir spada u jeftiniju klasu papira i namenjen je jednostavnijoj štampi. Loša strana ofsetnog papira je njegova upojnost, pa štampa u boji deluje nezasićeno, te zbog toga nije pogodan za štampanje velikih obojenih površina. Gramatura korišćenog ofsetnog papira je 80 $\mathrm{g} / \mathrm{m}^{2}$. Kunstrduk papir spada u grupu papira za umetničku štampu. Ovo je premazni papir, pa štampa na ovoj vrsti papira deluje luksuzno, boje deluju zasićenije, a manje je podložan gužvanju i upijanju štamparske boje. Postoje u mat i sjajnoj varijanti, a gramature kunstdruk papira kreću se od 90 do $350 \mathrm{~g} / \mathrm{m} 2$. U ovom radu korišćen je mat papir gramature $170 \mathrm{~g} / \mathrm{m}^{2}$. Tripleks karton spada u višeslojne kartone. Njihovi nazivi su najčešće vezani za broj slojeva, pa se tako tripleks karton sastoji od tri sloja, čiji je svaki sloj različitog sastava, boje ili gramature. U ovom radu korišćen je tripleks karton gramature $350 \mathrm{~g} / \mathrm{m}^{2}$. Kako bi se okarakterisale podloge za štampu korišćene u ovom eksperimentu, vršena su merenja beline, žutoće i površinske hrapavosti. Merena su za sva tri parametra vršena po 5 puta na različitim delovima tabaka, a zatim je izračunata srednja vrednosti. Srednje vrednosti izmerenih parametara za sve tri podloge prikazane su u tabeli 1.

Tabela 1. Belina, žutoća i hrapavost korišćenih podloga

\begin{tabular}{|l|c|c|c|}
\hline Podloga & $\begin{array}{l}\text { Belina } \\
(\text { Wcie })\end{array}$ & $\begin{array}{l}\text { Žutoća } \\
(\text { Y1925) }\end{array}$ & Hrapavost (Ra) \\
\hline Ofsetni papir & 109.40 & -11.36 & $3.825 \mu \mathrm{m}$ \\
\hline Kunstdruk papir & 107.56 & -9.02 & $0.427 \mu \mathrm{m}$ \\
\hline Tripleks karton & 76.68 & 0.12 & $1.340 \mu \mathrm{m}$ \\
\hline
\end{tabular}




\subsection{Ispitivanje vremenske ponovljivosti}

Kao osnova za ispitivanje vremenske ponovljivosti štamparskog sistema korišćen je program za sertifikaciju mašina za digitalnu štampu organizacije IDEAlliance (Idealliance Digital Press Certification).

Po ovom programu, potrebno je ispitati tri tabaka, pri čemu se drugi tabak štampa jedan sat, a treći 24 sata nakon prvog tabaka. Vremenska ponovljivost štampe procenjuje se na osnovu polja primarnih i sekundarnih boja, sa nanosom od $40 \%$ i $100 \%$, koja se nalaze na klinu za testiranje ponovljivosti.

Razlike u boji za CMYK i RGB polja mere se za sve kombinacije odštampanih tabaka, odnosno mere se razlike između prvog i drugog, drugog i trećeg, kao i prvog i trećeg tabaka. Da bi štamparski sistem prošao test, potrebno je da razlike u boji ispunjavaju uslov $\Delta \mathrm{E}_{00} \leq 3$ [5].

Vrednosti vremenskih razlika u boji za podlogu 1 ofsetni papir date su u tabelama 2 i 3. Postavljena je pretpostavka da će se na ovom papiru, usled hrapavosti neujednačenosti sastava papira, odsustva premaza i slično, javiti veće varijacije u boji.

Tabela 2. Razlike u boji primarnih i sekundarnih boja za polja punog tona na ofsetnom papiru

\begin{tabular}{|c|c|c|c|}
\hline Tabak & $\mathbf{1 ~ i ~ 2}$ & $\mathbf{2 ~ i ~ 3}$ & $\mathbf{1 ~ i ~ 3}$ \\
\hline Cijan & 0.81 & 1.09 & 0.90 \\
\hline Magenta & 0.96 & 1.18 & 0.45 \\
\hline Žuta & 1.63 & 0.92 & 1.05 \\
\hline Crna & 0.64 & 1.26 & 1.02 \\
\hline Crvena & 1.03 & 2.36 & 1.57 \\
\hline Zelena & 1.48 & 1.81 & 2.20 \\
\hline Plava & 0.88 & 0.92 & 0.51 \\
\hline
\end{tabular}

Tabela 3. Razlike $u$ boji srednjih tonova primarnih $i$ sekundarnih boja na ofsetnom papiru

\begin{tabular}{|c|c|c|c|}
\hline Tabak & $\mathbf{1} \mathbf{i} \mathbf{2}$ & $\mathbf{2 ~ i ~ 3}$ & $\mathbf{1 ~ i ~ 3}$ \\
\hline Cijan & 1.24 & 1.47 & 0.29 \\
\hline Magenta & 0.55 & 0.27 & 0.45 \\
\hline Žuta & 0.89 & 1.62 & 0.97 \\
\hline Crna & 1.42 & $\mathbf{3 . 9 1}$ & 2.67 \\
\hline Crvena & 0.55 & 0.57 & 0.17 \\
\hline Zelena & 1.44 & 1.97 & 2.10 \\
\hline Plava & 0.94 & 0.91 & 1.50 \\
\hline
\end{tabular}

U tabeli 3 primećuje se da jedna vrednost premašuje maksimalnu dozvoljenu vrednost programa za sertifikaciju. Kako je za uspešan test potrebno da vrednosti razlike u boji za sva polja budu manja od 3, zaključuje se da je vremenska ponovljivost sistema za podlogu 1 (ofsetni papir) neadekvatna.

Vrednosti vremenskih razlika u boji za podlogu 2 kunstdruk papir date su u tabelama 4 i 5 . Pretpostavka u vezi sa ovom podlogom je da će se, s obzirom na to da je reč o premaznom papiru za umetničku štampu, kvalitetnijeg sastava i karakteristika, javiti manje razlike u boji u odnosu na ofsetni papir.
Tabela 4. Razlike u boji primarnih i sekundarnih boja za polja punog tona na kunstdruk papiru

\begin{tabular}{|c|c|c|c|}
\hline Tabak & $\mathbf{1 ~ i ~ 2 ~}$ & $\mathbf{2 ~ i ~ 3}$ & $\mathbf{1 ~ i ~ 3}$ \\
\hline Cijan & 1.04 & 1.09 & 0.21 \\
\hline Magenta & 0.28 & 1.59 & 1.83 \\
\hline Žuta & 0.06 & 0.32 & 0.37 \\
\hline Crna & 0.44 & 0.67 & 0.43 \\
\hline Crvena & 0.25 & 1.37 & 1.50 \\
\hline Zelena & 0.27 & 0.77 & 0.62 \\
\hline Plava & 0.60 & 0.53 & 0.52 \\
\hline
\end{tabular}

Tabela 5. Razlike u boji srednjih tonova primarnih $i$ sekundarnih boja na kunstdruk papiru

\begin{tabular}{|c|c|c|c|}
\hline Tabak & $\mathbf{1 ~ i ~ 2}$ & $\mathbf{2 ~ i ~ 3}$ & $\mathbf{1 ~ i ~ 3}$ \\
\hline Cijan & 1.11 & 1.64 & 0.58 \\
\hline Magenta & 1.37 & 0.53 & 0.92 \\
\hline Žuta & 0.34 & 1.38 & 1.04 \\
\hline Crna & 1.48 & 1.26 & 0.23 \\
\hline Crvena & 0.57 & 2.36 & 1.90 \\
\hline Zelena & 0.55 & 0.62 & 0.97 \\
\hline Plava & 1.45 & 0.32 & 1.62 \\
\hline
\end{tabular}

Analizom tabela 4 i 5, zaključuje se da su sve vrednosti $\Delta \mathrm{E}$ razlike u boji u granicama tolerancija, pa je samim tim ponovljivost sistema za ovu podlogu adekvatna. Primećuje se da su na kunstdruk papiru vremenske varijacije u boji znatno manje u odnosu na ofsetni papir. Kada je reč o tripleks kartonu, njegova izrada, kao i sastav, nižeg su kvaliteta u odnosu na kunstdruk papir, pa se pretpostavlja da će se javiti razlike u boji nešto veće od onih na kunstdruk papiru. Vrednosti vremenskih razlika $u$ boji za tripleks karton date su u tabelama 6 i 7 .

Tabela 6. Razlike u boji primarnih i sekundarnih boja za polja punog tona na tripleks kartonu

\begin{tabular}{|c|c|c|c|}
\hline Tabak & $\mathbf{1 ~ i ~ 2 ~}$ & $\mathbf{2 ~ i ~ 3}$ & $\mathbf{1 ~ i ~ 3 ~}$ \\
\hline Cijan & 0.64 & 0.79 & 1.12 \\
\hline Magenta & 0.92 & 1.84 & 1.23 \\
\hline Žuta & 0.83 & 1.96 & 2.09 \\
\hline Crna & 1.43 & 1.82 & 0.52 \\
\hline Crvena & 0.69 & 1.09 & 1.26 \\
\hline Zelena & 1.24 & 2.50 & 1.57 \\
\hline Plava & 0.69 & 0.90 & 1.48 \\
\hline
\end{tabular}

Tabela 7. Razlike $u$ boji srednjih tonova primarnih $i$ sekundarnih boja na tripleks kartonu

\begin{tabular}{|c|c|c|c|}
\hline Tabak & $\mathbf{1}$ i 2 & $\mathbf{2 ~ i ~ 3}$ & $\mathbf{1 ~ i ~ 3 ~}$ \\
\hline Cijan & 1.49 & 1.18 & 2.30 \\
\hline Magenta & 1.67 & 1.94 & $\mathbf{3 . 3 6}$ \\
\hline Žuta & 0.62 & 1.57 & 1.67 \\
\hline Crna & 1.07 & $\mathbf{3 . 4 8}$ & $\mathbf{3 . 2 9}$ \\
\hline Crvena & 1.03 & $\mathbf{3 . 5 1}$ & $\mathbf{3 . 1 4}$ \\
\hline Zelena & 0.75 & 1.57 & 1.33 \\
\hline Plava & 1.16 & 1.14 & 1.74 \\
\hline
\end{tabular}


Kao što se može zaključiti iz tabele 7 , čak pet vrednosti prelazi maksimalnu dozvoljenu granicu razlike u boji. Ovo definitivno ne ispunjava uslove IDEAlliance programa za sertifikaciju, pa se ponovljivost štamparskog sistema sa ovom podlogom 3 smatra se neadekvatnom.

\subsection{Ispitivanje prostorne ponovljivosti}

U nastavku rada (tabele 8-10) prikazani su rezultati merenja za prostorne varijacije boja na tabaku. Mada se u Idealliance programu sertifikacije ne pominje prostorna ponovljivost, ona je podjenako značajna kao i vremenska. $\mathrm{S}$ obzirom na to da maksimalna vrednost prostornih razlika $\mathrm{u}$ boji nije definisana, koristiće se vrednost maksimalnih vremenskih varijacija, $\Delta \mathrm{E}_{00}=3$. Razlike u boji merene su po horizontalnoj i vertikalnoj osi, $\mathrm{tj}$. po osi kretanja tabaka (obimu fotocilindra), i po osi rotacije cilindra (širini fotocilindra).

Tabela 8. Prostorne razlike $u$ boji za procesne boje tabaku ofsetnog papira

\begin{tabular}{|c|c|c|c|c|}
\hline Pozicije & Cijan & Magenta & Žuta & Crna \\
\hline $1-3$ & 1.35 & 0.97 & 0.54 & 1.29 \\
\hline $3-5$ & 0.17 & 0.44 & 0.47 & $\mathbf{4 . 8 9}$ \\
\hline $5-7$ & 1.03 & 0.95 & 0.58 & 0.52 \\
\hline $1-7$ & 0.46 & 0.45 & 0.40 & $\mathbf{6 . 2 7}$ \\
\hline $4-8$ & 0.43 & 0.74 & 0.71 & 0.84 \\
\hline $2-6$ & 0.20 & 0.27 & 0.19 & 2.03 \\
\hline
\end{tabular}

Tabela 9. Prostorne razlike u boji za procesne boje tabaku kunstdruk papira

\begin{tabular}{|c|c|c|c|c|}
\hline Pozicije & Cijan & Magenta & Žuta & Crna \\
\hline $1-3$ & 0.82 & 0.38 & 0.05 & 1.14 \\
\hline $3-5$ & 0.57 & 0.80 & 0.43 & $\mathbf{6 . 4 4}$ \\
\hline $5-7$ & 0.96 & 0.75 & 0.28 & 1.47 \\
\hline $1-7$ & 0.64 & 0.74 & 0.36 & $\mathbf{5 . 4 4}$ \\
\hline $4-8$ & 0.44 & 0.66 & 0.70 & 0.61 \\
\hline $2-6$ & 0.19 & 0.30 & 0.40 & 2.53 \\
\hline
\end{tabular}

Tabela 10. Prostorne razlike u boji za procesne boje tabaku tripleks kartona

\begin{tabular}{|c|c|c|c|c|}
\hline Pozicije & Cijan & Magenta & Žuta & Crna \\
\hline $1-3$ & 0.25 & 0.35 & 0.07 & 0.34 \\
\hline $3-5$ & 0.59 & 0.36 & 0.66 & $\mathbf{3 . 8 2}$ \\
\hline $5-7$ & 0.39 & 0.37 & 0.67 & $\mathbf{3 . 0 9}$ \\
\hline $1-7$ & 0.51 & 0.57 & 0.45 & $\mathbf{6 . 7 6}$ \\
\hline $4-8$ & 0.27 & 0.35 & 0.49 & 0.62 \\
\hline $2-6$ & 0.14 & 0.67 & 0.38 & 0.25 \\
\hline
\end{tabular}

Uočava se da su u sva tri slučaja prostorne varijacije crne boje jako velike, i prelaze maksimalnu dozvoljenu vrednost $\Delta \mathrm{E}_{00}=3$.

Kako se za sve tri podloge uočava sličan trend, varijacije u boji ukazuju na neuiniformnost fotoreceptora. Može se zaključiti da se najveće varijacije u boji za sve tri podloge javljaju kod crne boje, dok je žuta boja najujednačenija. Što se tiče prostorne ponovljivosti, ona nije adekvatna ni za jednu od korišćenih podloga.

\section{ZAKLJUČAK}

Analizom razlika u boji, kada je reč o vremenskoj ponovljivosti, utvrđeno je da se najmanje razlike javljaju kod kunstdruk papira. To je takođe i jedina podloga koja ispunjava zahteve postavljene u Idealliance programu za sertifikaciju. Vremenska ponovljivost štampe za ostale dve podloge nije zadovoljavajuća.

Što se tiče prostorne ponovljivosti, donet je zaključak da je uniformnost fotoprovodnika od najvećeg značaja. Uočeno je da se u sva tri slučaja javljaju velike varijacije u crnoj boji, najčešće po širini fotocilindra, koje prelaze maksimalnu dozvoljenu vrednost, pa prostorna ponovljivost ove boje nije adekvatna. Za ostale tri boje nema odstupanja koje prelaze graničnu vrednost razlika $\mathrm{u}$ boji, a žuta boja pokazala se kao najujednačenija.

Ovaj rad predstavlja osnovu za ispitivanje ponovljivosti kod sistema na principu elektrofotografije sa suvim tonerom. Za dalja istraživanja neophodno je dodatno ispitati određene parametre, i obezbediti nepromenljive uslove za sprovođenje eksperimenta. Parametri koji su od značaja, i na koje posebno treba obratiti pažnju su vezani za mašinu za štampu i njene komponente, toner i podlogu za štampu, a kada je reč o kontrolisanom radnom okruženju prvenstveno se misli na konstantnu vlažnost vazduha, ambijentalnu temperaturu i slično.

Zbog razlike u količini prenetog tonera posebno treba obratiti pažnju na uniformno naelektrisanje fotoprovodnika, ujednačenost snage lasera, homogenost i uniformnost podloge za štampu, u smislu debljine, količine punioca, dielektričnih svojstva podloge, kao i na temperaturu pri fiksiranju tonera

\section{LITERATURA}

[1] H. Kipphan, "Handbook of Printmedia". 1st Ed. Berlin, Springer, 2001.

[2] R. Chung, "Color Repeatability of Spot Color Printing". Rochester Institute of Technology, Rochester, NY, 2005.

[3] T.P. Sim, "Sensing and Control for Color Consistency of the Xerographic Printing Process". University of Minnesota, 2009.

[4] I. Jurič, "Model za kontrolu površinske uniformnosti digitalnih otisaka". Departman za grafičko inženjerstvo i dizajn. Fakultet tehničkih nauka, Novi Sad, 2018.

[5] Idealliance, "Idealliance Digital Press Certification Program". [Online] Dostupno na: http://connect.idealliance.org/HigherLogic/System/Do wnloadDocumentFile.ashx?DocumentFileKey=ef430a e7-2fcc-cd3a-2ff3-eab28265eaa1

\section{Adresa za kontakt:}

MsC Miloš Krstić, krle.grid@gmail.com

Dr Nemanja Kašiković, knemanja@uns.ac.rs

Dr Ivana Jurič, rilovska@uns.ac.rs 